\title{
Clinical and Experimental Study on Thermoregulatory System and its Relation with Vasomotor Rhinitis
}

\author{
Somnath Saha, ${ }^{1}$ Nirmalya Kumar Majumder, ${ }^{2}$ D P Thombre ${ }^{3}$
}

\section{Introduction}

\section{$\underline{\text { ABSTRACT }}$}

Much of the perennial cold are of vasomotor origin still a less appreciated phenomenon even among the medical personnel, much of which is dubbed in a cursorily in the clinical analogue of a west paper wrap as 'allergic rhinitis'. This study was attempted to find out the role of thermoregulatory system with causation of vasomotor rhinitis and assessing role of hypothalamus in causation of vasomotor rhinitis.

\section{Materials and Methods}

In this study conducted during the period of July 1987 to August 1988, 20 normal adult individuals were taken as control and thermoregulatory study was done on them. The results were compared with cases of vasomotor rhinitis/non-allergic rhinopathy cases. In experimental study thermoregulatory study was done on albino rats before and after stereotaxis of anterior and posterior hypothalamic nuclei and the result were compared before stereotaxis and post stereotaxis.

\section{$\underline{\text { Results }}$}

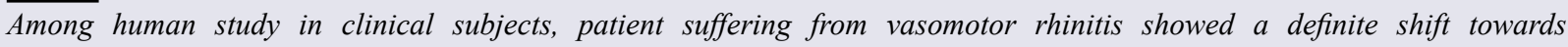
thermoregulatory imbalance both for generalized body caloric fluctuation and particularly on the nasal mucosa. Post-vidian neurectomy results for thermoregulation test was highly significant. In animal study post-hypothalamic stereotaxis temperature measurement showed minimal depression. Dorsal anterior hypothalamic lesion ablation showed significant derangement in the thermoregulatory tolerance profile of the rats'belly temperature. Posterior hypothalamic lesion showed that there may be some amount of derangements in the thermoregulatory tolerance, which however is not statistically conclusive. Thermoregulatory control is done at hypothalamus, particularly at anterior hypothalamic nuclei level and posterior hypothalamic nuclei in the brain. Thermoregulatory study proves a close correlation between non allergic rhinitis with imbalance in central thermal regulation by hypothalamus.

\section{Conclusion}

Thermoregulatory study in control and clinical subjects proves a close correlation between vasomotor rhinitis and sympathetic, parasympathetic system.

Kevwords

Rhinitis, Vasomotor; Body Temperature Regulation; Autonomic Nervous System; Hypothalamus; Denervation

$\mathrm{T}$ he term nonallergic vasomotor rhinitis (also called idiopathic rhinitis) means rhinitis symptoms that occur in relation to nonallergic, noninfectious triggers like: changes in temperature, humidity, and barometric pressure; exposure to strong odours, tobacco smoke, and exhaust fumes; and even the ingestion of certain foods. Up to $33 \%$ of patients with rhinitis are estimated to be of nonallergic rhinitis, and close to $65 \%$ of patients with allergic rhinitis also have symptoms that occur or worsen in the presence of nonspecific, nonallergic stimuli. ${ }^{1}$

Usually the primary symptoms observed are nasal obstruction and rhinorrhoea, with the term "vasomotor" suggesting involvement of neural, glandular, and vascular pathways.

Vasomotor rhinitis is the most common form of nonallergic rhinitis, comprising approximately $71 \%$

1 - Department of ENT, Medical College, Kolkata

2 - Department of ENT, JIPMER, Puducherry

3 - Department of Physiology, JIPMER, Puducherry

\section{Corresponding author:}

Dr Somnath Saha

email: sahasomnath11@gmail.com 
of all nonallergic rhinitis conditions. ${ }^{2}$ Its etiology and pathogenesis are imperfectly understood. Its diagnosis especially differentiation from other groups of rhinitis is difficult. The natural history is also variable and sometimes it remains undiagnosed in presence of other disabling diseases. Its treatment is also controversial and has changed from time to time. Due to rich autonomic supply of the nose, minimal changes of temperature, any neuroendocrinal change and emotional change can affect the nasal mucosa to a greater or lesser degree. Although the unified airway hypothesis indicates shared pathophysiological processes across both the upper and lower airways, ${ }^{3-5}$ the role of the autonomic nervous system (ANS) in nose and sinus symptoms is poorly understood. Historically, the capacity of the nasal vasculature to shrink and engorge in animals was known in the 1850 s and was histologically characterized as early as the $1950 \mathrm{~s}^{6}$

The important vasomodulatory effects of autonomic nerves in the nose were highlighted by Millonig et $\mathrm{al}^{7}$ in 1950 and further supported by evidence from cases of autonomic denervation in patients with nose symptoms. Konno and Togawa described, in 1979, the successful use of a vidian nerve section to improve symptoms of patients' allergic rhinitis. ${ }^{8}$ However, the transient results and variable benefits for different symptoms indicate a more complex relationship between the nose and the ANS. Alexander et al in their research studied the role of ANS dysfunction in sinonasal disease. The ANS is influenced by multiple factors, including personality and psychological distress, that causes the sinonasal symptoms. Further research will help to clarify the etiology of ANS dysfunction and its contribution to common systemic conditions. ${ }^{9}$ As hypothalamus is controlling the sympathetic and parasympathetic system of the body it is postulated that any hypothalamic imbalance specially changes in the molecular level and neurotransmitter level can cause a minimal sympathetic parasympathetic imbalance which can affect the thermoregulatory system of the body. This derangement of the thermoregulatory system can also occur via any endocrinal changes which also work through hypothalamus. In the present study, we tried to find out the role of thermoregulatory system and hypothalamus in the causation of vasomotor rhinitis.

\section{Materials and Methods}

\section{CLINICAL MATERIAL:}

The material of this clinical study consisted of 30 cases of vasomotor rhinitis and 20 controls seen and treated at Jawaharlal Institute of Postgraduate Medical Education and Research, Pondicherry during the period of July 1987 to August 1988.

\section{CASE:}

A case of vasomotor rhinitis was diagnosed based on the following criteria:

1) More than two attacks of rhinorrhoeic bouts/ month.

2) History of intolerance to temperature variation.

3) Alternate or both nostrils having persistent nasal blockage or nasal blockage without any general signs of nasal inflammation like malaise and fever.

4) Pale or congested edematous mucosa of nasal turbinates without any mucopus.

5) Radiology suggestive of mucosal hypertrophy with or without polypoidal changes, but not exhibiting any fluid level.

6) Nasal smear and peripheral blood not showing eosinophilic preponderance i.e. less than 6 cells/field which is normal in this area.

Any patient fulfilling a minimum of four criteria from the list above, including sixth which is the most confirmatory sign, was taken into the pool of our study.

\section{CONTROL:}

Normal adult siblings of the patients were studied (Total 20). After all this preliminary investigation, experimental study on control \& clinical subjects was conducted to examine the thermal influence on causation of cold. All the experiments were conducted in a thermoneutral laboratory (temperature $26 \pm 1^{\circ} \mathrm{C}$ ) using an indigenously devised thermocouple incorporated to 7P1 preamplifier of Grass Model 7 Polygraph with DC $15 \mathrm{~Hz}$ as low frequency and high frequency. The speed of the recording was usually $0.25 \mathrm{~mm} / \mathrm{sec}$. Normal palm and nasal mucosal temperature were recorded on clinical 


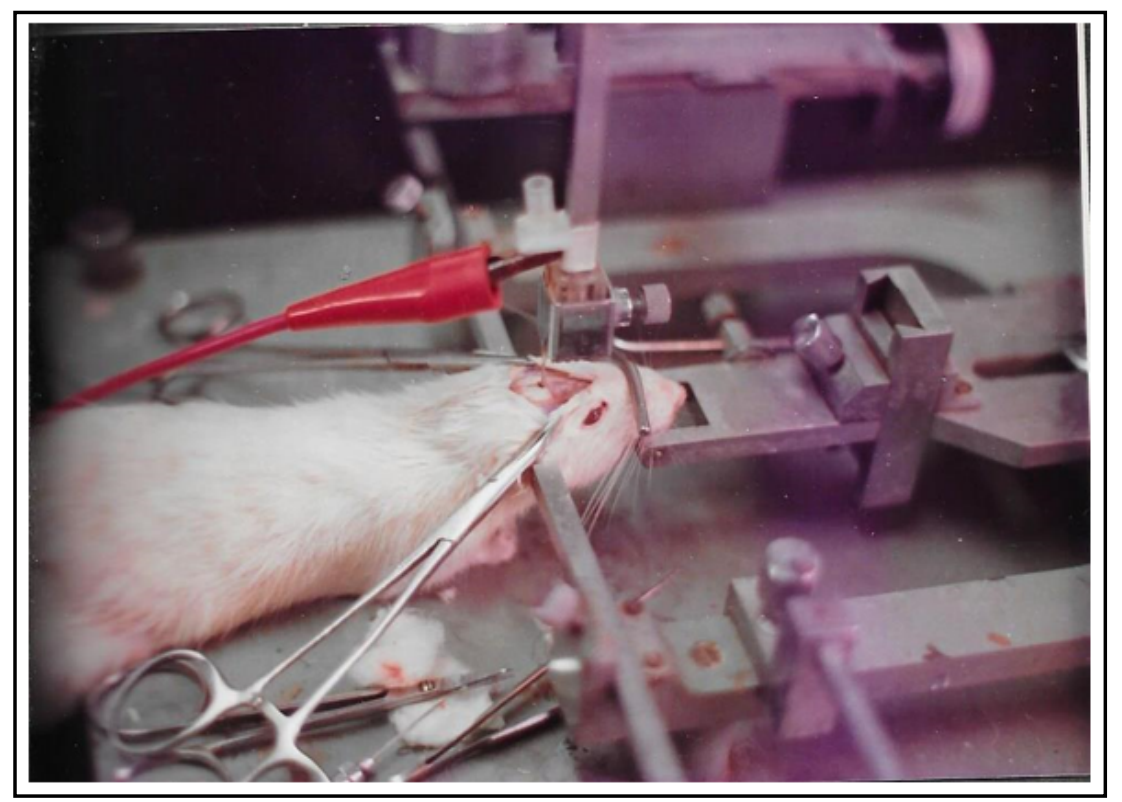

Fig. 1. Hypothalamic stereotaxis (anterior and posterior)

experimental subjects. After that all the experimental subjects were challenged with sudden exposure to cold. Cold challenge was presented to hand and nose.

The palm of the hand was cooled by dipping into ice cold water at $12^{\circ} \mathrm{C}$ for 3 minutes. Water from the hand was soaked by a filter paper to prevent heat gain by manual rubbing with towel. After that temperature of the palm was measured again for ten minutes and the time period over which the temperature of the palm regains its normal value was recorded. Similarly, the nose was irrigated with ice cold water at $12^{\circ} \mathrm{C}$. Residual water in the nasal cavity was soaked by keeping a piece of the filter paper in the dependent portion of the nose. Nasal temperature was recorded again and the time period over which it comes to its normal value was also recorded. During the post cooling temperature measurement, patient is asked to breathe through mouth, so that no caloric exchange took place between nasal air current and respiratory mucosa. Twenty controls were studied to evaluate the normal values.

Another series of 10 patients were taken up from the post vidian neurectomy group to note whether temperature changes can occur in the nasal mucosa after vidian nerve section.

\section{EXPERIMENTAL STUDY:}

Experimental study on western Albino rats was done to know the influence of autonomic nervous system on mammalian nasal mucosa. A total of twenty rats were used for the experimental purpose to assess the autonomic denervation at the level of hypothalamus and its relationship with cold exposure. In ten experimental rats, dorsal anterior hypothalamus stereotaxis was done with the help of neurophysiologist. (Fig. 1) Coordinates for the desired area of lesion were determined according to stereotaxis atlas for the rats. ${ }^{10}$ Stereotaxis apparatus (INCO) was used. Bilateral electrolytic lesions were made by using a current of two to three amperes from INCO lesion maker for fifteen seconds. Before the lesion all the rats' normal belly temperature and post cooling temperature (after cooling with $12^{\circ} \mathrm{C}$ water for 3 minutes) of the belly were recorded. Post lesion rats were again then subjected to thermoregulatory study after 3 weeks to examine any post stereotaxis temperature variation with cold challenge test and the results were analyzed. Similarly, posterior hypothalamic lesion was done in 10 albino rats. (Fig. 2) 




Fig.2. Rat Brain section showing electrolytic lesion in a) Posterior hypothalamus, b) Anterior hypothalamus.

\section{Results}

Thermoregulatory profile was done for control group and clinical patients. Experimental cold challenge test was done in both groups and the temperature changes are measured by a thermocouple attached with Grass Model 7 Polygraph.

Control group shows return to normal temperature after initial cooling of hand and nasal mucosa for specified time as per methodology already described. Mean period of return to normal temperature in hand was $335.5 \mathrm{sec}$. varying from 200 to 600 seconds. In nose the mean period to return to normal temperature 101.58 sec. varying from 80 -120 seconds (Table I)

Vasomotor rhinitis patients show a poor vasomotor response as evidenced by a delayed return to normal temperature (Mean value in hand $746 \mathrm{sec}$., mean value in nose $250.5 \mathrm{sec}$ ). All the data are subjected to statistical analysis by unpaired ' $t$ ' test and compared to normal and 'p' value calculated. In both hands and nose it is less than 0.001 which is highly significant (Table II).

Post-vidian neurectomy patients (Table III) were examined similarly. Their hands' temperature record was still abnormal but time period over which the nose was coming back to normal after cold challenge test, shows a major shift towards normalcy (Mean value 263 sec. to $103 \mathrm{sec}$.). Statistical analysis was done by paired ' $\mathrm{t}$ ' test and 'p' value calculated $(\mathrm{P}<0.001)$ which was highly significant.

\section{ANIMAL EXPERIMENT:}

A total of 20 rats were used for this experiment. In 10 rats, dorsal anterior hypothalamic stereotaxis was done. Before the lesion, all the rats' belly temperatures were measured. Average belly temperature for the control rats was $34-37^{\circ} \mathrm{C}$. Cold challenge test was done on the rats' belly and temperature was recorded. Similarly, temperature was recorded after the lesion using thermocouple and Grass Model 7 Polygraph.

Temperature was recorded in rats with posterior hypothalamic lesion also in similar manner. After anterior hypothalamic stereotaxis there was elevation of the belly temperature ranging from $34.6^{\circ} \mathrm{C}$ to $39^{\circ} \mathrm{C}$, average $37.61^{\circ} \mathrm{C}$. In posterior hypothalamic lesion, it was observed that there was a minimal lowering of the body temperature ranging from $32-37^{\circ} \mathrm{C}$ (Mean value $34.25^{\circ} \mathrm{C}$ ). All the data were statistically analyzed (paired t test) and $p$ value was calculated. It was seen that $p$ value was significant for anterior hypothalamic 
Table I: Control group of patients

\begin{tabular}{|c|c|c|c|c|}
\hline \multirow{2}{*}{$\begin{array}{l}\text { SL. } \\
\text { NO. }\end{array}$} & \multicolumn{2}{|c|}{ NORMAL TEMPERATURE } & \multicolumn{2}{|c|}{$\begin{array}{l}\text { AFTER COLD CHALLENGE TEST (AVERAGE } \\
\text { TIME TAKEN TO COME BACK TO NORMAL) }\end{array}$} \\
\hline & HAND TEMP( $\left({ }^{\circ} \mathrm{C}\right)$ & NOSE TEMP $\left({ }^{\circ} \mathrm{C}\right)$ & HAND & NOSE \\
\hline 1 & 33 & 34 & $600 \mathrm{sec}$ & $80 \mathrm{sec}$ \\
\hline 2 & 34 & 33 & $440 \mathrm{sec}$ & $90 \mathrm{sec}$ \\
\hline 3 & 35 & 34 & $200 \mathrm{sec}$ & $100 \mathrm{sec}$ \\
\hline 4 & 33 & 34 & 330 sec & $90 \mathrm{sec}$ \\
\hline 5 & 36 & 36 & $400 \mathrm{sec}$ & $100 \mathrm{sec}$ \\
\hline 6 & 35 & 35 & $360 \mathrm{sec}$ & $100 \mathrm{sec}$ \\
\hline 7 & 33 & 34 & $200 \mathrm{sec}$ & $100 \mathrm{sec}$ \\
\hline 8 & 31 & 35 & $380 \mathrm{sec}$ & $120 \mathrm{sec}$ \\
\hline 9 & 33 & 33 & $280 \mathrm{sec}$ & $90 \mathrm{sec}$ \\
\hline 10 & 32 & 35 & $200 \mathrm{sec}$ & $110 \mathrm{sec}$ \\
\hline 11 & 33 & 35 & $260 \mathrm{sec}$ & $60 \mathrm{sec}$ \\
\hline 12 & 30 & 34 & $280 \mathrm{sec}$ & $115 \mathrm{sec}$ \\
\hline 13 & 34 & 35 & $400 \mathrm{sec}$ & $120 \mathrm{sec}$ \\
\hline 14 & 32 & 37 & $280 \mathrm{sec}$ & $110 \mathrm{sec}$ \\
\hline 15 & 32 & 38 & $300 \mathrm{sec}$ & $115 \mathrm{sec}$ \\
\hline 16 & 33 & 31.5 & $360 \mathrm{sec}$ & $90 \mathrm{sec}$ \\
\hline 17 & 32 & 32.5 & $400 \mathrm{sec}$ & $80 \mathrm{sec}$ \\
\hline 18 & 34 & 33 & $400 \mathrm{sec}$ & $140 \mathrm{sec}$ \\
\hline 19 & 32 & 32.5 & $360 \mathrm{sec}$ & $120 \mathrm{sec}$ \\
\hline 20 & 33 & - & $280 \mathrm{sec}$ & - \\
\hline
\end{tabular}

lesion ( $\mathrm{p}$ value $<0.001$ ). (Table IV)

\section{Discussion}

The hypothalamus is a very small, but extremely important part of the diencephalon that is involved in the mediation of endocrine, autonomic and behavioral functions. Recent studies divide the hypothalamus rostrocaudally into four regions: preoptic, supraoptic, tuberal, and mammillary regions. Each region consists of several nuclei, whose functions were defined mainly using lesions, stimulations, and genetic approaches. The anterior hypothalamic nucleus is a nucleus of the hypothalamus. Its function is thermoregulation (cooling) of the body. Damage or destruction of this nucleus causes hyperthermia. The anterior hypothalamic 
Table II: Patients selected for surgery (Vasomotor Rhinitis)

\begin{tabular}{|c|c|c|c|c|}
\hline SL NO. & $\begin{array}{c}\text { NASAL } \\
\text { TEMP }\left({ }^{\circ} \mathrm{C}\right)\end{array}$ & $\begin{array}{c}\text { HAND } \\
\text { TEMP }\left({ }^{\circ} \mathrm{C}\right)\end{array}$ & $\begin{array}{c}\text { TIME TAKEN FOR HAND } \\
\text { TEMPERATURE TO COME } \\
\text { BACK TO NORMAL AFTER } \\
\text { COLD CHALLENGE(SEC) }\end{array}$ & $\begin{array}{l}\text { TIME TAKEN FOR THE } \\
\text { NASAL TEMPERATURE } \\
\text { TO COME BACK TO } \\
\text { NORMAL (SEC) }\end{array}$ \\
\hline 1 & 31 & 31 & 1200 & 240 \\
\hline 2 & 32 & 31 & 680 & 240 \\
\hline 3 & 35 & 35 & 600 & 250 \\
\hline 4 & 34 & 35 & 880 & 280 \\
\hline 5 & 35 & 33 & 680 & 280 \\
\hline 6 & 35 & 32 & 800 & 260 \\
\hline 7 & 33 & 32 & 700 & 280 \\
\hline 8 & 34 & 35 & 600 & 220 \\
\hline 9 & 35 & 35 & 520 & 220 \\
\hline 10 & 37 & 33 & 500 & 240 \\
\hline 11 & 35 & 37 & 800 & 200 \\
\hline 12 & 36 & 32 & 960 & 280 \\
\hline 13 & 36 & 32 & 760 & 360 \\
\hline 14 & 34 & 33 & 680 & 250 \\
\hline 15 & 32 & 34 & 700 & 220 \\
\hline 16 & 34 & 33 & 800 & 270 \\
\hline 17 & 34 & 33 & 900 & 260 \\
\hline 18 & 36 & 34 & 760 & 200 \\
\hline 19 & 35 & 32 & 800 & 220 \\
\hline 20 & 34 & 31 & 600 & 240 \\
\hline
\end{tabular}

region is sometimes grouped with the preoptic area. ${ }^{11}$ The posterior nucleus of the hypothalamus is one of the many nuclei that make up the hypothalamic region of the brain. Its functions include elevation of blood pressure, pupillary dilation, and shivering or body heat conservation (thermoregulation). ${ }^{12}$

The hypothalamus has the most complex circuitry of any brain region. Like other brain areas there are neural interconnections. But unlike other brain areas, there are also extensive non-neural communication pathways between the hypothalamus and other brain regions and the periphery.

The circuits are named as limbic circuits, sensory and autonomic circuits and neuro-humoral connections. The role of the hypothalamus in regulation of homeostasis is result of proper interconnection between these circuits. 
Table III: Estimation of nasal temperature before and after vidian neurectomy.

\begin{tabular}{|c|c|c|c|c|}
\hline \multirow[b]{2}{*}{ SL. NO. } & \multicolumn{2}{|r|}{ BEFORE SURGERY } & \multicolumn{2}{|c|}{ AFTER SURGERY } \\
\hline & $\begin{array}{c}\text { NASAL } \\
\text { TEMP }\left({ }^{\circ} \mathrm{C}\right)\end{array}$ & $\begin{array}{c}\text { TIME TAKEN FOR NASAL } \\
\text { TEMP TO COME BACK TO } \\
\text { NORMAL(SEC) }\end{array}$ & $\begin{array}{c}\text { NASAL } \\
\text { TEMP }\left({ }^{\circ} \mathbf{C}\right)\end{array}$ & $\begin{array}{c}\text { TIME TAKEN TO COME } \\
\text { BACK TO NORMAL } \\
\text { TEMP(SEC) }\end{array}$ \\
\hline 1 & 34 & 280 & 35 & 120 \\
\hline 2 & 35 & 280 & 36 & 100 \\
\hline 3 & 35 & 260 & 36.5 & 80 \\
\hline 4 & 33 & 280 & 38 & 90 \\
\hline 5 & 34 & 220 & 37 & 110 \\
\hline 6 & 35 & 220 & 35 & 100 \\
\hline 7 & 37 & 240 & 36.5 & 120 \\
\hline 8 & 35 & 200 & 37 & 110 \\
\hline 9 & 36 & 280 & 36.5 & 90 \\
\hline 10 & 36 & 360 & 36 & 110 \\
\hline & Before Sur & $\begin{array}{r}\text { Surgery: Average value }=103 \mathrm{sec} \\
\text { Degree of free } \\
\text { After surgery on comparison ' } P \text { ' } v a\end{array}$ & $\begin{array}{l}=13.37 \mathrm{sec} . \\
9 \\
<0.001 \text { (Sig) }\end{array}$ & $\begin{array}{l}\text { t'value }=10.34 \\
=4.23 \\
\text { at) }\end{array}$ \\
\hline
\end{tabular}

Insult on one circuit results in disturbances in other. We by our experimental and clinical study tried to establish relationship of the thermoregulatory circuits with vasomotor rhinitis which is an autonomic dysfunctional problem.

Adaptive heat production (thermogenesis) in a cold environment, such as shivering, is triggered by cold sensation delivered from thermoreceptors in the skin to the thermoregulatory brain centre, preoptic area (POA) of the hypothalamus. The thermosensory information from the skin is transmitted to the lateral parabrachial nucleus (LPB) of the brainstem through the spinal cord and this information is further transmitted from the LPB to the POA. Cold and warm sensory pathways are mediated by separate populations of neurons in the
LPB. Rats whose spinal-LPB-POA neural pathways are interrupted cannot promptly produce heat in a cold environment, dissipate body heat in a hot environment, or choose comfort thermal environment, indicating that these thermosensory neural pathways play a critical role in autonomic and behavioral defense of body temperature from ambient cold and heat. ${ }^{13}$

The temperature change and its relation with nasal mucosa was studied by Drettner. ${ }^{14}$ The nasal temperature showed a tendency to rise with rise in outdoor temperature. Cooling of the back was associated with decrease in nasal temperature and this cooling is greater in women than men. Also cooling of feet was accompanied by transient reduction of nasal temperature and this decrease is greater than cooling of back. The 
Table IV: Animal Studies

\begin{tabular}{|c|c|c|c|}
\hline \multirow[b]{2}{*}{ SL. NO. } & CONTROL & $\begin{array}{c}\text { LESION I (POSTERIOR } \\
\text { HYPOTHALAMIC } \\
\text { LESION) }\end{array}$ & $\begin{array}{c}\text { LESION II (ANTERIOR } \\
\text { HYPOTHALAMIC } \\
\text { LESION) }\end{array}$ \\
\hline & $\begin{array}{l}\text { TEMP MEASURED BY } \\
\text { THERMOCOUPLE- } \\
\text { FILLED WITH GRASS } \\
\text { MODEL '7' POLYGRAPH } \\
\text { (C) }\end{array}$ & $\begin{array}{l}\text { TEMP MEASURED } \\
\text { AFTER } \\
\text { POSTHYPOTHALAMIC } \\
\text { ELECTROLYTIC } \\
\text { LESION (C) }\end{array}$ & $\begin{array}{l}\text { TEMP MEASURED } \\
\text { AFTER DORSAL } \\
\text { HYPOTHALAMIC } \\
\text { ELECTROLYTE } \\
\text { LESION(C) }\end{array}$ \\
\hline 1 & 34.8 & 32 & 37 \\
\hline 2 & 35 & 33 & 37 \\
\hline 3 & 36 & 35 & 39 \\
\hline 4 & 37 & 35 & 38 \\
\hline 5 & 35 & 34 & 38 \\
\hline 6 & 34 & 33 & 34.6 \\
\hline 7 & 36 & 35 & 38 \\
\hline 8 & 34.8 & 35 & 38 \\
\hline 9 & 34 & 34 & 38.5 \\
\hline 10 & 34 & 37 & 39 \\
\hline \multirow{3}{*}{$\begin{array}{c}\text { STASTICAL } \\
\text { ANALYSIS } \\
\text { (Paired 't' test) }\end{array}$} & Average value $=35.06 \mathrm{C}$ & $\mathrm{AV}=34.25 \mathrm{C}$ & $\mathrm{AV}=37.61 \mathrm{C}$ \\
\hline & Standard Deviation $=\mathbf{1 . 0 0 2}$ & $\mathrm{SD}=1.39$ & $\mathrm{SD}=1.3$ \\
\hline & Standard Error $=\mathbf{0 . 3 1 7}$ & $\mathrm{SE}=0.443$ & $\mathrm{SE}=0.41$ \\
\hline
\end{tabular}

nasal passage exhibited gradually progressive narrowing especially marked after discontinuation of cooling. Also cooling of the inspiratory air caused pronounced fall of nasal temperature and nasal passage became narrower during inspiration of cold air. General skin cooling also caused the narrowing of nasal passage. They also did the same cooling experiment on persons with allergic or non-allergic rhinopathy at the period when subjects were in normal phase. There was marked swelling at the end of the cold which was in general similar to those in the normal persons. There was relatively pronounced tendency of blanching of nasal mucosa during the exposure to the cold, followed by a bluish discoloration.

In present study a poor thermoregulatory balance was noticed in all cases of vasomotor rhinitis in comparison to control group, as evident by history of cold intolerance and cold challenge test in hand and nose $(\mathrm{P}<0.001)$ both in hand and nose by unpaired ' $t$ ' test. Again, in post vidian neurectomy cases, hand temperature remains abnormal while the nose temperature is coming back to normal level ( $\mathrm{P}<0.001$ by paired ' $\mathrm{t}$ ' test - highly significant) due to parasympathetic ablation. This is due to very close relation of thermoregulatory centres in hypothalamus and its association with sympatheticparasympathetic centre. ${ }^{15}$ Any thermal stimulus can stimulate the thermoregulatory centre of the body on exposure to thermal change. This, in turn, causes an imbalance in sympathetic-parasympathetic system which act upon the very sensitive tissue of the nasal mucosa resulting in congestion and rhinorrhoea. 
Dorsal anterior hypothalamic lesion: Temperature study after lesion of this region was suggestive of the hyperthermia indicating that parasympathetic and thermoregulatory centres are in very close proximity with each other and a dorsal anterior hypothalamic lesion can cause temperature imbalance in experimental albino rats $(\mathrm{P}<0.001)$. In anterior hypothalamic lesions the rectal temperature even reaches $43^{\circ} \mathrm{C}$ and anterior hypothalamus acts on the heat-dissipating centre of the body. ${ }^{15}$

Posterior hypothalamic lesion: In posterior hypothalamic lesion, thermoregulatory study showed there was minimal depression of the temperature in the post stereotaxis rat in comparison to the normal. (Average time $34.25 \mathrm{sec}$. ' $t$ ' value 1.488, not significant).

Eccles and Lee found maximal vasoconstrictor response were elicited in the hypothalamus anterior to mammillary body and in the central grey matter of mesencephalon. ${ }^{16}$ Secondly, there is central autonomic control which extended to area 6 and 8 .

\section{Conclusion}

Thermoregulatory control is done at hypothalamus, particularly at anterior and posterior hypothalamic nuclei in the brain. Thermoregulatory study in control and clinical subjects proves a close correlation between vasomotor rhinitis and sympathetic, parasympathetic system via hypothalamus in the body.

\section{Acknowledgement}

This is the thesis work of Dr.Somnath Saha, done under the guidance of the professor and Head of the Dept. of ENT, Dr. N.K.Majumder at JIPMER and electrophysiological experiment was carried out at Physiology Dept. of JIPMER with kind permission of Dr. Thombre.

\section{Statement of informed consent}

Informed consent taken from all the clinical \& control subjects on a preformed proforma.

\section{Statement of human and animal rights}

The first author states with supporting documents that he had necessary permission from the institution to perform the procedures.

\section{Editor Comments}

Though the study was conducted in 1986-87, the findings of the study are still relevant and studies on this subject are very few since then.

\section{References}

1. Kaliner MA, Farrar JR. Consensus review and definition of nonallergic rhinitis with a focus on vasomotor rhinitis, proposed to be known henceforth as Nonallergic Rhinopathy Part 1. Introduction. The World Allergy Organization Journal 2009, 2(6):97

2. Settipane RA. Epidemiology of vasomotor rhinitis. World Allergy Organ J. 2009; 2(6):115-8

3. Stachler RJ. Comorbidities of asthma and the unified airway. Int Forum Allergy Rhinol. 2015; 5(suppl 1):S17-S22

4. Frieri M, Kumar K, Boutin A. Review: Immunology of sinusitis, trauma, asthma, and sepsis. Allergy Rhinol (Providence) 2015; 6:205-14

5. Frieri M. Asthma linked with rhinosinusitis: An extensive review. Allergy Rhinol (Providence) 2014; 5:41-9

6. Dawes JD, Prichard MM. Studies of the vascular arrangements of the nose. J Anat. 1953; 87:311-22

7. Millonig AF, Harris HE, Gardner WJ. Effect of autonomic denervation on nasal mucosa; interruption of sympathetic and parasympathetic fibers. Arch Otolaryngol. 1950; 52:359-72

8. Konno A, Togawa K. Role of the vidian nerve in nasal allergy. Ann Otol Rhinol Laryngol. 1979; 88(pt. 1):258-66

9. Yao A, Wilson JA, Ball SL. Autonomic nervous system dysfunction and sinonasal symptoms. Allergy \& rhinology (Providence, R.I.) 2018; 9, 2152656718764233. doi:10.1177/2152656718764233

10. König JFR, Klippel RA. The Rat Brain. A stereotaxic Atlas of the Forebrain and Lower Parts of the Brain Stem. Williams and Wilkins, Amsterdam 1963

11. Onoe $\mathrm{H}$, Watanabe $\mathrm{Y}$, Ono K, Koyama Y, Hayaishi O. Prostaglandin E2 exerts an awaking effect in the posterior hypothalamus at a site distinct from that mediating its febrile action in the anterior hypothalamus. J. Neurosci. 1992;12 (7): 2715-25 PMID 1613554 
12. Fundamental neuroscience for basic and clinical applications Haines Duane E, Ard MD. 4th ed. Philadelphia, PA: Elsevier/ Saunders. 2013. ISBN 9781437702941 . OCLC 794603152

13. Nakamura K, Morrison SF. A thermosensory pathway mediating heat-defense responses. Proceedings of the National Academy of Sciences of the United States of America 2010; 107(19), 8848-53 doi:10.1073/pnas.0913358107

14. Drettner B. Vascular reactions of the human nasal mucosa on exposure to cold. Uppsala: Acta oto-laryngologica, suppl. 1961;166, 109 pages

15. Barrett K E, Barman SM, Yuan JX-J, Brooks H. Ganong's Review of Medical Physiology, 26th Ed. 2019; New York, McGraw-Hill Education LLC

16. Eccles R, Lee RL. The influence of the hypothalamus on the sympathetic innervation of the nasal vasculature of the cat. Acta Otolaryngol (Stockh) 1981; 91:127-34. 